\title{
COMPUTER SIMULATION TO OPTIMIZE THE VFA ALPHA PROTOTYPE WITH A HYDRAULIC PISTON COMPRESSOR AND AN INTEGRATED BOOSTER
}

\author{
A. Mezulis ${ }^{1 *}$, A. Safronov², J. Guzeyeva², J. Begens ${ }^{2}$ \\ ${ }^{1}$ Institute of Solid State Physics, University of Latvia, 8 Kengaraga Str., Riga, \\ LV-1063, LATVIA \\ ${ }^{2}$ Hygen Ltd., 7 Peldu Str., Jelgava, LV-3002, LATVIA \\ *e-mail: ansis.mezulis@cfi.lu.Iv
}

Natural gas, including biomethane, is a sustainable alternative fuel. Widening compressed natural gas applications by now is restricted by weakly developed infrastructure. Hygen Ltd. works on "hydraulic piston" technology for natural gas and biomethane compressing, storing, delivering and discharging the storage cylinders by means of an innovative hydraulic boosting technology. Designing of the Vehicle Fuelling Appliance (VFA) demands to take into account thermodynamics and gas dynamics properties at fluid compression and motion. The present paper deals with theoretical characteristics and their link to test measurements regarding a particular VFA HYGEN+ Alpha prototype manufactured by Hygen Ltd.

Keywords: Gas compression, gas refuelling, gas storage, gas thermodynamics, Matlab simulation, reservoir engineering and simulation.

\section{INTRODUCTION}

Nowadays the alternative fuels are defined by the Directive of the European Parliament and of the Council on the deployment of alternative fuel infrastructure (DAFI). One of them is natural gas (NG), including biomethane - the upgraded biogas, which is considered the renewable fuel with close to zero greenhouse gas emissions in Well-to-Wheel scale. DAFI sets out minimum requirements for the building-up of alternative fuel infrastructure, includ- ing refuelling points to be implemented by means of Member States' national policy frameworks [1]. On 21 January 2020, the European Biogas Association (EBA), the Natural \& bio Gas Vehicle Association (NGVA Europe) and the European Automobile Manufacturers' Association (ACEA) called on the EU policy makers to accelerate the deployment of infrastructure to deliver natural gas and renewable gas/biomethane across the European Union [2]. 
Technical problems of widening the compressed natural gas (CNG) and bio-gas (bio-CNG) application under off-grid conditions are as follows:

- $\quad$ storage cylinder filling to high pressure in an efficient and cost-effective way;

- $\mathrm{CNG} /$ bio-CNG delivery to the destination (injection point to the grid or fuelling station);

- development of an efficient fuelling appliance;

- complete gas storage cylinder dischargement.

To solve these technical problems, in 2008 Latvian engineer Aleksey Safronov invented and patented a new method for hydraulic compression of gaseous fuels and a device for implementation thereof [3]. A manufacturer from Latvia Hygen Ltd. [4] has developed a "hydraulic piston" technology intended for gas compression, accu- mulation and discharge, and implemented it in various $\mathrm{CNG}$ fuelling systems. Unlike conventional mechanical multistage compressors, the technology of hydraulic piston uses a method of gas compression by means of a working fluid, which is pushed by a sufficiently powerful hydraulic pump. The technology of hydraulic compression allows building autonomous modules to be placed on the mobile carrier.

Technical innovation of the "hydraulic piston" technology described in the present paper is the boosting stage that accomplishes gas fuelling after the free flow stage up to reaching the nominal pressure in the receiver cylinder. Developed to the vehicle fuelling appliance level, the hydraulic compressor module with a boosting regime solves the technical problems stated above in small and even medium amount of the demanded gas supply.

\section{EXPERIMENTAL: WORKING STAGES OF THE HYDRAULIC COMPRESSOR}

\subsection{COMPRESSION AND GAS STORAGE STAGE}

Technology of hydraulic piston com- cylinder is explained in Fig. 1. pression and compressed gas storage in a

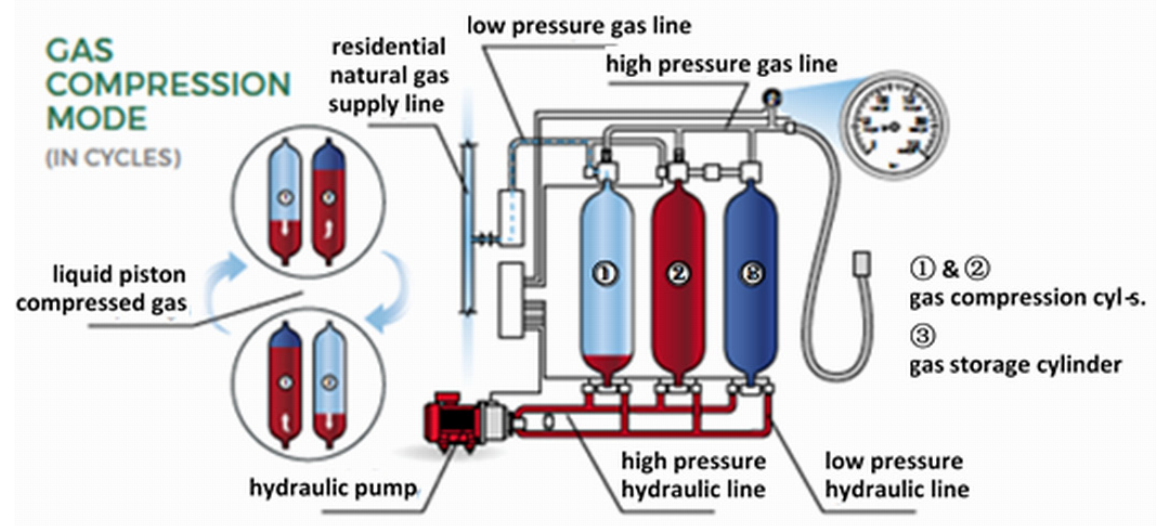

Fig. 1. Hydraulic piston compressor and storage. 
Cylinders 1 and 2 work as compressors. The amount of the working liquid (red fill in Fig. 1) slightly exceeds the volume in one compression cylinder. The working liquid is chosen to avoid any chemical reaction with the gas, as well as have minimized gas diffusivity. Typical working liquid for a gas piston is transmission oil. By rotating the hydraulic pump and triggering the valves, the working liquid is alternatively pumped between the first and second compression cylinders. Increasing the amount of liquid in a compressor cylinder causes compression of low-pressure gas above the liquid. At the same time, a decrease of liquid in another compression cylinder makes use for inlet of a new portion of low-pressure gas. In the present Alpha prototype volume free of liquid is $26 \mathrm{~L}$, productivity of the hydraulic pump is $8.64 \mathrm{~L} / \mathrm{min}$, and the resulting compression step is 3 minutes long. Inlet gas pressure can vary in wide range, starting from residential low pressure of 17-25 mbar up to industrial high pressures. Too low gas inlet pressure considerably reduces the efficiency of compressing; therefore, for low pressure a pre-compression up to 3 bars is accomplished. At the end phase of each compression cycle, when gas pressure in the compression cylinder surpasses that in the storage cylinder, a current portion of gas is pushed through the check valve into the storage cylinder. As a result of compression in multiple cycles, storage cylinder 3 is filled up with the gas, up to 200 bars. Driving all hydraulic and gas valves is implemented by the electronic control unit.

Computer simulation of the compression stage is useful not only to see the number of compression cycles to fill the storage cylinder, but also to see thermal characteristics. Note that the average outlet temperature of the gas must not reach the safety threshold of any type of a standard fuel tank, starting from $60^{\circ} \mathrm{C}$.
For the simulation, we use Matlab Simscape elements with their mathematical description (Ref. [5] for Subsections 2.1 and 2.2). For the storage cylinder a constant volume chamber is chosen. The enclosure of this element can exchange mass and energy with the connected gas network, as well as exchange heat with the environment, allowing its internal pressure and temperature to evolve over time. Mass $M$ conservation relates the mass flow rate $\dot{\mathrm{m}}_{\mathrm{A}}$ to the dynamics of the pressure $p$ and temperature $T$ of the internal node $I$, representing the gas volume

$\frac{\partial \mathrm{M}}{\partial \mathrm{p}} \cdot \frac{\mathrm{dp}_{\mathrm{I}}}{\mathrm{dt}}+\frac{\partial \mathrm{M}}{\partial \mathrm{T}} \cdot \frac{\mathrm{dT}_{\mathrm{I}}}{\mathrm{dt}}=\dot{\mathrm{m}}_{\mathrm{A}}$.

Energy $U$ conservation relates the energy $\Phi_{\mathrm{A}}^{\cdot}$ and heat flow $\dot{Q}_{H}$ rates to the dynamics of the pressure and temperature of the internal node, representing the gas volume

$\frac{\partial U}{\partial p} \cdot \frac{d p_{\mathrm{I}}}{d t}+\frac{\partial U}{\partial T} \cdot \frac{d T_{\mathrm{I}}}{d t}=\dot{\Phi}_{A}+\dot{Q}_{H}$.

As the gas enters the storage cylinder by small portions every 3 minutes, the overall temperature within the cylinder has enough time to equilibrate. Consequently, no convective heat exchange is considered, and the cylinder body can be represented as the thermal mass

$\dot{Q}_{H}=c m_{c y l} \frac{d T}{d t}$,

where $c$ is specific heat capacity of material of the cylinder. The outer surface of the cylinder is in convective thermal contact with the ambient air.

Each compression cylinder represents the translational volume $V$ converter. The mass and energy conversation equations are similar to those of a constant volume chamber, except for an additional term in each equation 
$\frac{\partial M}{\partial p} \cdot \frac{d p_{\mathrm{I}}}{d t}+\frac{\partial M}{\partial T} \cdot \frac{d T_{\mathrm{I}}}{d t}+\rho_{\mathrm{I}} \frac{d V}{d t}=\dot{m}_{A}$

$\frac{\partial U}{\partial p} \cdot \frac{d p_{\mathrm{I}}}{d t}+\frac{\partial U}{\partial T} \cdot \frac{d T_{\mathrm{I}}}{d t}+\rho_{\mathrm{I}} h_{\mathrm{I}} \frac{d V}{d t}=\dot{\Phi}_{A}+\dot{Q}_{H}$,

where $\rho$ and $h$ are density and specific enthalpy of the internal node $I$. A correct description of heat exchange between compressed gas and thermal bodies in the compression cylinder is very complicated. Increase in the amount of the working liquid in the cylinder increases its thermal mass; on the other hand, this process decreases the area of cylinder body that is in

\subsection{FREE FLOW STAGE}

By filling a target tank of initial pressure lower than 200 bars, the first filling stage is free flow stage. This stage lasts until pressure equilibrium between the storage tank and the target tank is achieved.

The pipeline, in which viscous friction forces act, as well as local restrictions have to be taken into account carefully. The Alpha prototype device has M8x1 steel tube of $2 \mathrm{~m}$ long, which is connected to $3 / 8$ " of $4 \mathrm{~m}$ long outer rubber tube in free gas flow circuit. For Matlab simulation, we take a pipe, which accounts for viscous friction losses and convective heat transfer with the pipe wall. The pressure and temperature in the pipe evolve based on the compressibility and thermal capacity of the gas volume. Choking occurs when the outlet reaches the sonic condition. The mass and energy conversation equations are as follows:

$\frac{\partial M}{\partial p} \cdot \frac{d p_{\mathrm{I}}}{d t}+\frac{\partial M}{\partial T} \cdot \frac{d T_{\mathrm{I}}}{d t}=\dot{m}_{A}+\dot{m}_{B}$,

$\frac{\partial U}{\partial p} \cdot \frac{d p_{\mathrm{I}}}{d t}+\frac{\partial U}{\partial T} \cdot \frac{d T_{\mathrm{I}}}{d t}=\dot{\Phi}_{A}+\dot{\Phi}_{B}+\dot{Q}_{H}$,

where $A$ denotes inlet, and $B$ is an outlet port of the pipe. contact with the compressed gas. Additionally, at the temperature above $100-200{ }^{\circ} \mathrm{C}$ the energy loss due to thermal radiation is not negligible. Such a complicated model is not the aim of the present study. We restrict our theoretical model by creating a link between it and test experiment data, which helps evaluate the main characteristics of the fans, which are necessary for cooling the heads of compressor cylinders. Thermal parameters of the gas pipeline play a minor role because at the compression stage gas is transmitted via pipeline by small discrete portions.

The momentum balance for each half from the middle point $I$ of the pipe models the pressure drop due to momentum flux and viscous friction

$p_{A}-p_{\mathrm{I}}=\left(\frac{\dot{m}_{A}}{S}\right)^{2} \cdot\left(\frac{1}{\rho_{\mathrm{I}}}-\frac{1}{\rho_{A}}\right)+\Delta p_{A I}$,

$p_{B}-p_{\mathrm{I}}=\left(\frac{\dot{m}_{B}}{S}\right)^{2} \cdot\left(\frac{1}{\rho_{\mathrm{I}}}-\frac{1}{\rho_{B}}\right)+\Delta p_{B I}$,

where $\Delta p_{A I}$ and $\Delta p_{B I}$ are pressure losses due to viscous friction, which are distinguished for laminar and turbulent flow, and $S$ is the cross-sectional area. The upper Reynolds number of laminar flow $R e$ is commonly chosen as 2000, and in the laminar flow regime the pressure losses due to viscous friction are as follows:

$$
\begin{aligned}
& \Delta p_{A I(\text { lam })}=f_{s h} \frac{\dot{m}_{A} \cdot \mu_{I} \cdot L}{4 \rho_{I} \cdot S \cdot D_{h}^{2}} ; \\
& \Delta p_{B I(\text { lam })}=f_{s h} \frac{\dot{m}_{B} \cdot \mu_{I} \cdot L}{4 \rho_{I} \cdot S \cdot D_{h}^{2}},
\end{aligned}
$$

where $f_{\text {sh }}$ - the shape factor for laminar flow viscous friction, $\mu$-dynamic viscosity, $L-$ pipe length, $D_{h}$ - hydraulic diameter. The turbulent flow starts from the lower Reynolds number of turbulent flow, which is 
usually taken as 4000 . For turbulent flow regime

$$
\begin{aligned}
& \Delta p_{A I(\text { tur })}=f_{\text {Dar }} \frac{\dot{m}_{A} \cdot\left|\dot{m}_{A}\right| \cdot L}{4 \rho_{I} \cdot D_{h} \cdot S^{2}} ; \\
& \Delta p_{B I(\text { tur })}=f_{\text {Dar }} \frac{\dot{m}_{B} \cdot\left|\dot{m}_{B}\right| \cdot L}{4 \rho_{I} \cdot D_{h} \cdot S^{2}} .
\end{aligned}
$$

Note that in turbulent flow the laminar shape factor $f_{s h}$ is replaced by the Darcy friction factor $f_{D a r}$, which is widely computed from the Haaland correlation

$$
f_{\text {Dar }}=\left[-1.8 \log \left(\frac{6.9}{R e}+\left(\frac{\varepsilon_{r}}{3.7 D_{h}}\right)^{1.11}\right)\right]^{-2}
$$

The absolute roughness of internal surface $\varepsilon_{r}$ of different materials can be found in the tables. We take $0.05 \mathrm{~mm}$ for a commercial steel tube and $0.002 \mathrm{~mm}$ for the liner of the rubber tube.

The flow regime of the Reynolds number $2000-4000$ is mixed. The pressure losses due to viscous friction in the mixed regime follow a smooth connection between those in the laminar flow and those in the turbulent flow.

The convective heat transfer equation between the pipe wall and the gas volume is governed by the Newton's law of cooling

$\dot{Q}_{H}=\propto_{T} \frac{4 S L}{D_{h}}\left(T_{H}-T_{I}\right)$.

The heat transfer coefficient $\alpha_{T}$ depends on the Nusselt number

$\propto_{T}=\left(\frac{N u_{A}+N u_{B}}{2}\right) \cdot \frac{\lambda}{D_{h}}$,

where $\lambda$ is thermal conductivity of the fluid. The Nusselt numbers $N u_{A}$ and $N u_{B}$ depend on the flow regime. The Nusselt numbers in the laminar flow regime are constant and equal to the set value, which is usually 3.66. The Nusselt numbers in the turbulent flow regime are computed from the Gnielinski correlation
$N u_{(t u r)}=\frac{(R e-1000) \operatorname{Pr}_{I} \frac{f_{\text {Dar }}}{8}}{1+1.27 \cdot\left(P r_{i}^{1.5}-1\right)\left(\frac{f_{\text {Dar }}}{8}\right)^{0.5}}$,

where $\operatorname{Pr}$ is the Prandtl number: $\operatorname{Pr}=c_{p} \mu / \lambda$. The Nusselt numbers in the mixed regime follow a smooth connection between those in the laminar flow and those in the turbulent flow.

In the case of flow choking, the mass flow rates out of the pipe at ports $A$ and $B$ are as follows:

$\dot{m}_{A(C h)}=\rho_{A} v_{A} S ; \quad \dot{m}_{B(C h)}=\rho_{B} v_{B} S$,

where $v_{A}, v_{B}$ are the speed of sound at ports $A$ and $B$, respectively.

The choked pressure is obtained by substituting the choked mass flow rate into the momentum balance equations for the pipe. For the port $A$

$p_{A(C h)}=p_{I}+\left(\frac{\dot{m}_{A(C h)}}{S}\right)^{2}$.

$\cdot\left(\frac{1}{\rho_{I}}-\frac{1}{\rho_{A}}\right)+\Delta p_{A I(C h)}$.

$\Delta p_{A(C h)}$ is the pressure loss due to viscous friction, assuming that the choking has occurred.

At the free flow stage, gas molecules enter the receiver cylinder at high velocity; therefore, a convective heat exchange (forced convection) between the gas and the cylinder body takes place [6]. In a particular case, the velocity of gas and its direction relative to the cylinder body, as well as other parameters are far from being constant. Since the aim of the present Matlab simulation is to get theoretical characteristics of medium accuracy, the authors evaluate for use the mean value of the convective heat exchange coefficient $\alpha_{T}$ for a particular setup of $300 \mathrm{~W} / \mathrm{m}^{2} \cdot \mathrm{K}$. The heat exchange between outer surfaces of all cylinders and ambient air is considered to be the air free 
convection with a coefficient of $10 \mathrm{~W} / \mathrm{m}^{2} \cdot \mathrm{K}$.

Presence of a significant pressure drop causes acting the Joule-Thomson effect within a non-ideal gas. Numerically, the Joule-Thomson effect is characterised as follows:

$$
\mu_{J-T}=\left(\frac{\partial T}{\partial p}\right)_{H}
$$

where the index $H$ represents a partial derivative at constant enthalpy. The Joule-

\subsection{BOOSTING STAGE}

In order to empty storage cylinder 3 (Fig. 1) of gas far behind the free flow level, the boosting mode is implemented. The principle of boosting is displayed in Fig. 2.

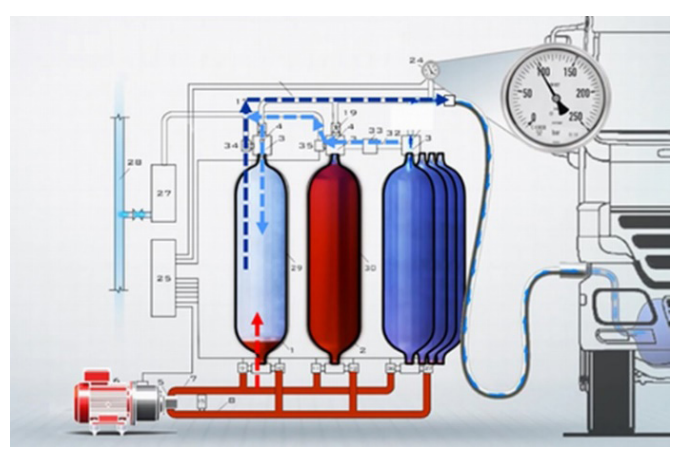

Fig. 2. Hydraulic piston operating in a boosting mode.

When the storage tank is connected to the vehicle receptacle, fuelling occurs by free flow until pressure equilibrium is achieved. After the free flow stage, the remaining mid-pressure gas from the storage cylinder (light blue arrow) is supplied to the compressing cylinder for boosting, where it is further compressed by the hydraulic piston and forced out directly
Thomson effect in natural gas is widely investigated; nevertheless, taking it into account is rather complicated because its value strongly depends on absolute pressure and temperature [7], [8]. As a solution, Matlab simulation allows building multidimensional data arrays, in a particular case, $\mu_{J-T}(p, T)$. Since the inlet of the target tank is the only location for a significant pressure drop, we address all temperature drop due to the Joule-Thomson effect to entering gas in the target tank.

into the vehicle fuel tank (dark blue arrow). Boosting cycles repeat alternately in two compression cylinders. The number of boosting cycles to achieve the pressure of 200 bars in the vehicle fuel tank depends on the volume and initial pressure of the tank. In case of a mid-sized tank of $240 \mathrm{~L}$, about 10 single boosting cycles are enough to fill the vehicle completely. Obviously, if VFA contains two compressors, the number of boosting cycles must be divided by two.

From the mathematical simulation point of view, the boosting stage combines the models of free flow and compression. Choking, turbulent and Joule-Thomson effects at the boosting stage from the storage to the compressor cylinder are not so intense as at the free flow stage because of less initial pressure difference and higher ratio between donor and receiver volumes (190 L vs. 26 L for one compressor cylinder). As the gas inlet pressure is more than ten times higher (30.. 120 bars vs. 3 bars), the transferred mass portion from each compression cycle at the boosting stage is significantly larger than that at the compression stage. 
VFA HYGEN+ Alpha prototype consists of two compressors (four cylinders, $32 \mathrm{~L}$ each) and storage volume (four cylinders, $95 \mathrm{~L}$ each). One must be careful to simulate the stages regarding only one compression cylinder. At the compression stage, each compression cylinder fills one fourth of storage volume; thus, the storage volume must be taken of $95 \mathrm{~L}$ for a correct stored
NG mass growth. At the free flow stage, the compressor is not employed, and all storage volume of $380 \mathrm{~L}$ must be simulated. The boosting stage is the most complicated case: a half of storage volume fills the compression cylinder of one pair, and, in turn, one compression pair boosts a half of the target tank. Ambient air temperature, as in Northern Europe, is taken $20^{\circ} \mathrm{C}$.

\subsection{SIMULATION OF THE GAS COMPRESSION AND STORAGE STAGE}

Matlab simulation of the gas compression and storage stage is based on Eqs. (1)(5), and the obtained main characteristics are shown in Fig. 3. For better resolution only last $120 \mathrm{~min}$ of the whole compression is displayed, i.e., from 185 to 205 bars (ending pressure of the compression is adjusted a bit over 200 bars as a correction to following cool-down of receiver cylinders). Stored mass of NG increases in equal steps, as NG inlet amount in the compression cylinder ("donor" in Fig. 3) is constant and not depending on the end pressure. The pressure in the storage cylinder ("receiver" in Fig. 3) also grows in equal steps, as its temperature increases very slightly.

The temperature growth of NG at compressing to gradually higher pressures has to be restricted at the end of process not to reach the safety threshold of any gas cylinder type. As the donor temperature at compressing is higher at the boosting stage, the necessary temperature restriction by means of installing the fans is optimized at a latter stage.

Figures $3 c, 3 d$ show that temperature of the gas in the pipeline during the idle time of mass transfer relaxes in a rather wide range.

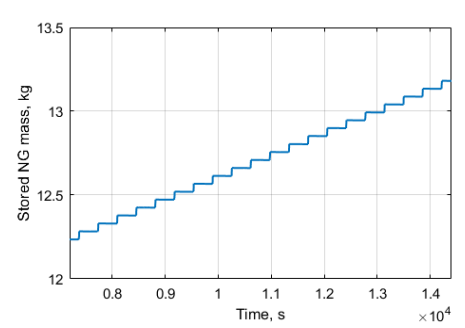

a)

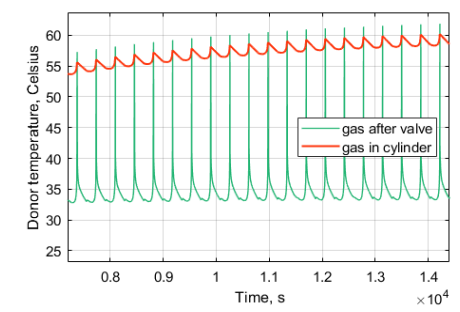

c)

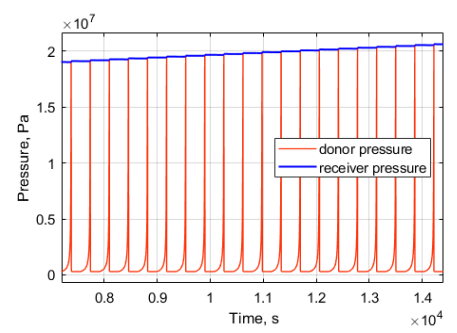

b)

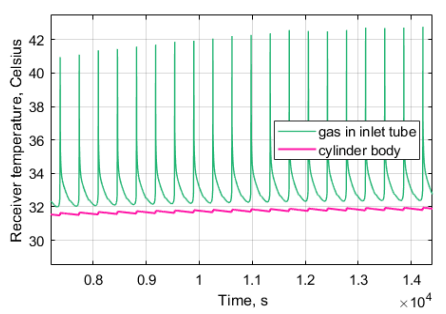

d)

Fig. 3. Matlab simulated physical characteristics of the gas compression and storage stage. 


\subsection{SIMULATION OF THE FREE FLOW STAGE}

Matlab simulation of the free flow stage basically regards Eqs. (6)-(9) with addition of Eqs. (10)-(18). Figure 4 depicts the obtained main characteristics of the free flow stage. The vehicle tank is assumed as mid-sized, $240 \mathrm{~L}$, with the initial pressure of 10 and 80 bars. Figure $4 \mathrm{~b}$ shows that equilibrium pressure at the end of the free flow stage is ca. 128

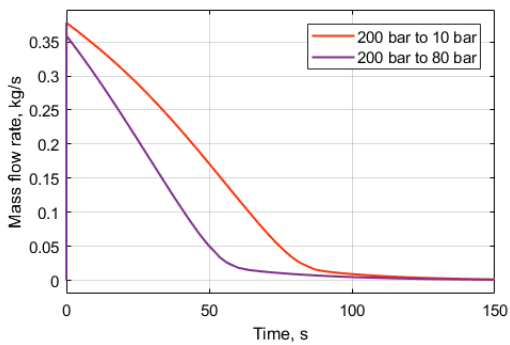

a)

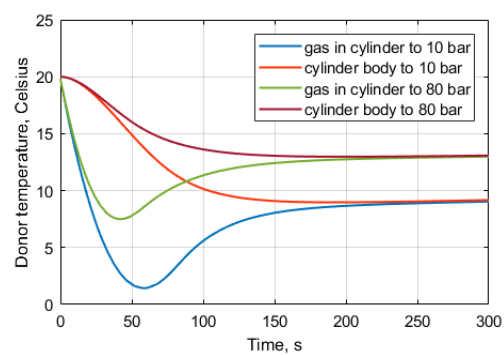

c) and 158 bars, respectively. According to thermodynamics, the temperature of $\mathrm{NG}$ in the donor cylinder is rapidly decreasing, whereas in the receiver cylinder increasing during high NG mass flow rate (Figs. 4c, 4d). Very low temperature of $\mathrm{NG}$, entering the receiver cylinder at the initial stage, is caused by acting the JouleThomson effect.

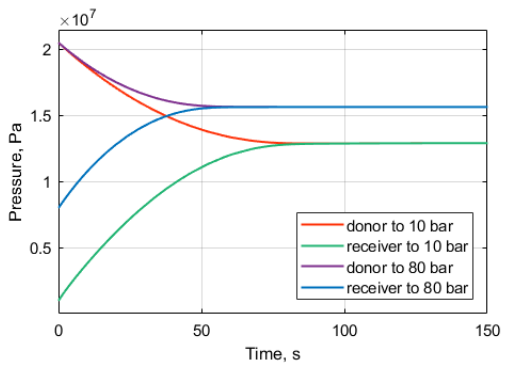

b)

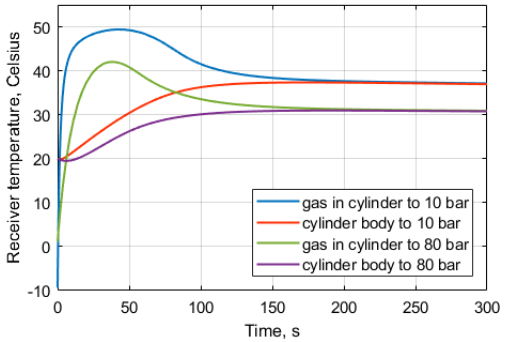

d)

Fig. 4. Matlab simulated physical characteristics of the free flow stage.

\subsection{SIMULATION OF THE BOOSTING STAGE}

The boosting stage includes both the free flow and compression stages; therefore, all equations cited above are used in Matlab simulation, Eqs. (1)-(9) with addition of Eqs. (10)-(18). Figure 5 depicts the obtained main characteristics of the boosting stage for the case of $240 \mathrm{~L}$ target tank with initial pressure of 10 bars. The whole boosting process, which follows the free flow stage and lasts 30 minutes, is dis- played.

Boosted mass of NG increases in descending steps, as NG source is the storage cylinders with restricted volume. The pressure (Fig. 5b) in the target tank increases in descending steps as well, reaching preset 205 bar in 5 boosting steps performed by one compressor cylinder of the pair.

The temperature growth in the compressor ("donor" in Fig. 5c) cylinder is 
of major interest. As said above, it has to be restricted at the end of process. Matlab simulation without the forced convective air flow around the heads of compressor cylinders returns an overheating by 15-20 ${ }^{\circ} \mathrm{C}$. We estimate the dissipated power $P$ that results in the heat excess. In the first-order approximation we assume that excess heat dissipates from the surface at the head of compression cylinder, twice its cross-section, $0.075 \mathrm{~m}^{2}$. Thus, $P=c m \Delta T / \tau=125 \mathrm{~W}$, where $\tau$ is the period of compression cycles, equal to $360 \mathrm{~s}$. Calculators, tables and plots to find necessary parameters of a fan are widely accessible. We use a simple calcula-

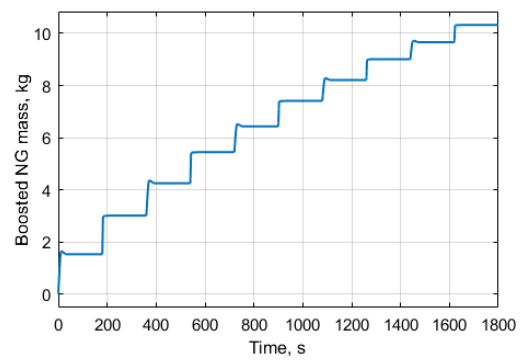

a)

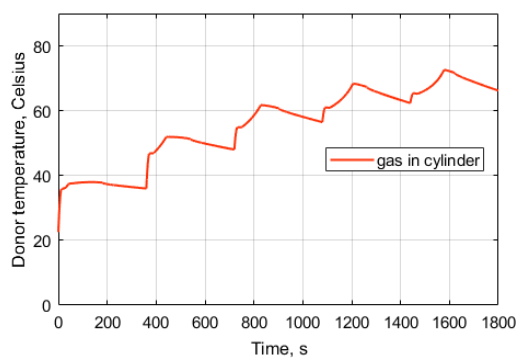

c) tor designed by Stego Ltd. [9]. For a device, designed for Northern and Central Europe, we choose maximum ambient temperature as $40{ }^{\circ} \mathrm{C}$ and designed interior temperature as $65^{\circ} \mathrm{C}$. With the power dissipation of 125 $\mathrm{W}$, the calculator returns the required volume flow of $15.5 \mathrm{~m}^{3} / \mathrm{h}$ that can be ensured by a medium-sized fan. Including the determined cooling parameters in Matlab simulation, as a result, we get average temperature growth from $40{ }^{\circ} \mathrm{C}$ to $72{ }^{\circ} \mathrm{C}$ approximately (Fig. 5c), which is quite acceptable taking into account that there is the amount of $\mathrm{NG}$ at temperature below $40{ }^{\circ} \mathrm{C}$ in the target tank after the free flow stage.

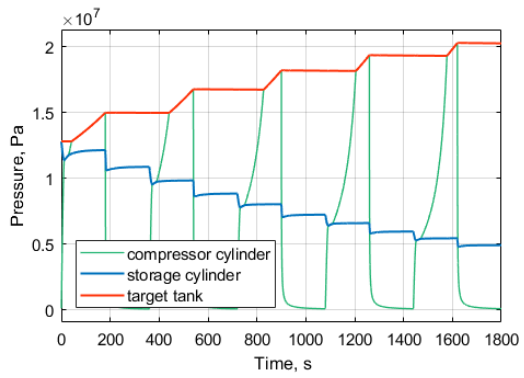

b)

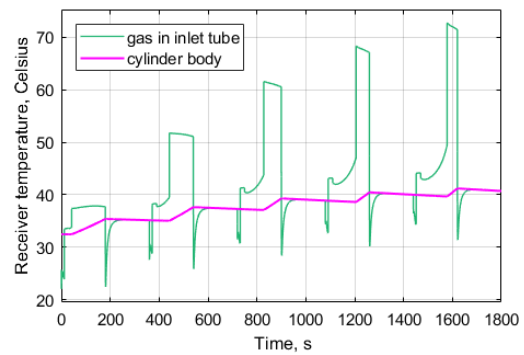

d)

Fig. 5. Matlab simulated physical characteristics of the boosting stage.

\subsection{APPLYING THE RESULTS OF SIMULATION TO HYGEN+ ALPHA PROTOTYPE}

To test the HYGEN+ Alpha prototype, we install customary manometers in gas tubing nodes. Installing the pressure measuring sensors of high precision inside the cylinders and gas tubing is a rather complicated task due to maximum pressure of 200 bars and rapid temperature changes. Moreover, accurate dynamic pressure measurements for the prototype is not of great necessity. A lot of publications are available, which testify a good accordance between theoretical and experimental pressure curves, e.g., 
Ref. [10]. The main results of testing the prototype regard the refuelled amount of $\mathrm{NG}$, especially the efficiency of boosting technology, and, in addition, avoiding the overheating and frosting.

In HYGEN+ Alpha prototype tests, all three stages explained above proved to work properly. Refuelling the target tanks of volume less than $350 \mathrm{~L}$ occurs up to 205 bars with the help of the boosting technology. Number of necessary boosting cycles as well as readings of the manometers and of the NG counter are in good accordance with Matlab graphs displayed above.

Heating the heads of compressor cylinders at the compression and boosting stages is of major interest. Figure 6 depicts the temperature measurements of NG in outlet from the compression cylinder at the ending part of both stages. Note that the boosting stage is 10x expanded in time for a better resolution. At the boosting stage, the average ending temperature value reaches $74{ }^{\circ} \mathrm{C}$ at linear temperature growth of $1.1^{\circ} \mathrm{C} / \mathrm{min}$. The simulation (Fig. 5c) predicts $72{ }^{\circ} \mathrm{C}$ and approximately the same growth of $1.1 \pm 0.1^{\circ} \mathrm{C} / \mathrm{min}$.

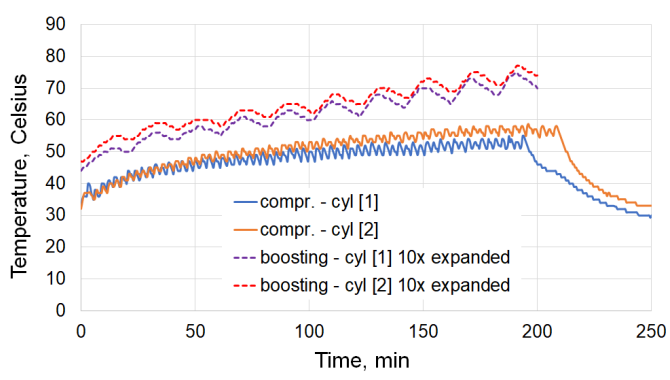

Fig. 6. Temperature measurements from compression and boosting stages with HYGEN+ Alpha prototype.

An important parameter for the compressor type device is its power consumption. As measured, the total electrical consumption of the HYGEN+Alpha prototype to fill a target tank of $240 \mathrm{~L}$ from 10 to 205 bars is $2.04 \mathrm{kWh}$, whereas from 80 to 205 bars $-1.12 \mathrm{kWh}$. Regarding the whole refuelling process, the gas storage stage has to be added. It takes ca. 48 hours and consumes $34.8 \mathrm{kWh}$.

\section{DISCUSSION}

Matlab simulation allows creating mathematical models for all three stages. At the compression and boosting stages, the main attention is paid to gas temperature growth in the compression cylinder. Inlet NG mass portion of each compression cycle at the boosting stage is significantly larger than that at the compression stage that results in more intense heating of the heads of compression cylinders. The parameters of cooling fans are chosen by first-order approximation of overheated surface and by using a fan calculator. Inconsistency between the theory and the practice turns out to be only $3 \%$ in ending temperature values $\left(72{ }^{\circ} \mathrm{C}\right.$ vs. $74{ }^{\circ} \mathrm{C}$ ). In relation to that, we predicted a bit lower theoretical value due to a simplified theoretical model, which accounts the temperature equilibrium between the gas and thermal bodies. All obtained temperature data are in a safety region and can be corrected in practice by choosing the fans of different parameters. A slight rise in temperature of the receiver cylinder at the compression and boosting stages is observed in simulation as well as in practice. It causes no threats but is the reason why refuelling is worth to be a little over-pressured.

At the free flow stage, a well-known phenomenon is a rapid temperature decrease below zero Celsius degrees. It occurs in the donor cylinder due to gas state 
equations, whereas in the receiver cylinder due to acting the Joule-Thomson effect within a non-ideal gas. With the particular VFA HYGEN+ the parameters are chosen so that the hydrate formation line may be crossed during a too short period of time to create the hydrates. Regarding the receiver cylinder, in the first few seconds of filling the temperature of gas inside the cylinder is usually below zero Celsius degrees. In practice, we use the mesh filter in the receiver inlet to convince that hydrates have not formed in this critical location.

The hydraulic boosting stage that is considered to be an innovation in VFA devices comes across the technical problem not to damage the hydraulic pump by inlet overpressure. This pressure in the first boosting cycle typically is $80-120$ bars, which is considerably larger than the allowed maximal inlet pressure of ca. 50 bars. In the particular VFA, it is solved by supplying the remaining mid-pressure gas from the storage cylinder in a point of time after the hydraulic pump starts to fill the compression cylinder with a working liquid. Thus, the remaining gas causes pressure on the outlet of hydraulic pump.

We noticed that due to physical reasons the boosting stage at too low NG pressure in the storage cylinders became inefficient, especially, in terms of the consumed electric power versus the transferred NG mass. It occurs only when filling very large target tanks. With target tanks less than 350 $\mathrm{L}$ refuelling up to full 205 bars is still costeffective.

\section{CONCLUSIONS}

The company from Latvia Hygen Ltd. has designed an innovative technology of the hydraulic piston employment in natural gas and biogas compression, allowing one to produce various cost-effective and convenient high-pressure gas storage and vehicle fuelling appliances. When designing an Alpha prototype of a particular gas compression and boosting device, it is highly important to predict thermodynamic characteristics, especially those which indicate possible overheating or frosting. Matlab simulation can give a wide spectrum of numerical results, which are in line with practice, and helps choose parameters and necessary installations to avoid overheating or frosting in critical points. Moreover, it is possible to perform computer simulation of the VFA device for hydrogen enriched natural gas fuel (HCNG) with different hydrogen content [11], [12]. The use of HCNG becomes more and more topical in today's world due to applying hydrogen technologies to enforce the Paris Agreement on climate change [13], as stated by the European Commission in 2020 [14], [15].

\section{ACKNOWLEDGEMENTS}

The research has been supported by the European Regional Development Fund project "Competence Centre of Mechanical Engineering", contract No.1.2.1.1/18/A/008 signed between the Competence Centre of Mechanical Engineering and the Central Finance and Contracting Agency, Research No. 3.1 "Additional research and integra- 
tion of the technology of hydraulic piston, aiming to develop and demonstrate economically efficient compressed natural gas smart commercial vehicle fuelling appliance". Our special gratitude to Gaspard Bouteau, PhD, Research Engineer, who conducted research in Engie Lab CRIGEN.
Scientific co-authorship of the Laboratory of Materials for Energy Harvesting and Storage, ISSP UL has been supported by the Ministry of Economics of the Republic of Latvia, project LAGAS No VPP-EMINFRA-2018/1-0003.

\section{REFERENCES}

1. Directive 2014/94/EU of the European Parliament and of the Council of 22 October 2014 on the deployment of alternative fuels infrastructure. Official Journal of European Union 2014: L 307/1.

2. Natural and Renewable Gas: Joint Call to Accelerate the Deployment of Refuelling Infrastructure. (n.d.). (Accessed 15 February 2020). Available at https:// www.ngva.eu/medias/joint-call-for-theacceleration-of-the-deployment-of-naturaland-renewable-gas-and-its-refuellinginfrastructure-across-the-eu-pr/

3. World Intellectual Property Organisation. (Accessed 16 February 2020). Available at https://patentscope.wipo.int/search/ en/detail.jsf?docId=WO2009035311\&_ cid=P11-K6YVV3-37117-1

4. Hygen Ltd., Company from Riga, Latvia. (n.d.). (Accessed 18 May 2020). Available at http://www.hygengroup.com

5. MathWorks Help Center. (Accessed 10 March 2020). Available at https://www. mathworks.com/help/simulink/, https:// www.mathworks.com/help/physmod/ simscape/index.html

6. Kuntz, K.J. (1994). Modeling the fast fill process in natural gas vehicle storage cylinders. Institute of Gas Technology, Chicago, USA, Corpus ID: 108118392. Available at https://www.semanticscholar. org/paper/Modeling-the-fast-fill-processin-natural-gas-Kountz/3e40bdba523381 ef3 dd5bff7e9036943fb75218d

7. Tarom, N., Mofazzal Hossain, Md., \&
Azar, R. (2018). A New Practical Method to Evaluate the Joule-Thomson Coefficient for Natural Gases. J. Petrol Explor. Prod. Technol., 8, 1169-1181, DOI: 10.1007/ s13202-017-0398-Z

8. Maric, I. (2005). The Joule-Thomson Effect in Natural Gas Flow-Rate Measurements. J. Flow Measurement and Instrumentation, 16, 387-395, DOI: $10.1016 / \mathrm{j}$. flowmeasinst.2005.04.006

9. Stego Connect, Inteligent Condition Management, Germany (Accessed 10 March 2020). Available at https://www. stego-group.com/nc/services/calculationtools/cooling-calculation/

10. Dutton, J.C., \& Coverdill, R.E. (1997). Experiments to Study the Gaseous Discharge and Filling of Vessels. Int. J. Engineering Education, 13 (2), 123-134.

11. Kahraman, N., Akansu, S.O., \& Aydin, K. (2009). Investigation of Combustion Characteristics and Emissions in a Spark Ignition Engine Fuelled with Natural GasHydrogen Blends. International Journal of Hydrogen Energy, 34 (2), 1026-1034.

12. Morrone, B., \& Unich., A. (2009). Numerical Investigation on the Effects of Natural Gas and Hydrogen Blends on Engine Combustion. International Journal of Hydrogen Energy, 34 (10), 4626-4634.

13. Paris Agreement of Climate Change, Council of the European Union (Accessed 18 May 2020). Available at https://www. consilium.europa.eu/en/policies/climatechange/paris-agreement/ 
14. Communication from the Commission to the European Parliament, the Council, the European Economic and Social Committee and the Committee of the Regions. Powering a climate-neutral economy: an EU Strategy for Energy System Integration. Available at https://op.europa.eu/en/publication-detail/-/ publication/5ba29377-c135-11 ea-b3a401aa75ed71a1/
15. Communication from the Commission to the European Parliament, the Council, the European Economic and Social Committee and The Committee of the Regions. A hydrogen strategy for climate-neutral Europe. Available at https://op.europa.eu/ en/publication-detail/-/publication/5602f358c136-11ea-b3a4-01aa75ed71a1/ 